\title{
Rohstoff Mensch
}

\section{Erhard Taverna}

Dr. med., Mitglied der Redaktion

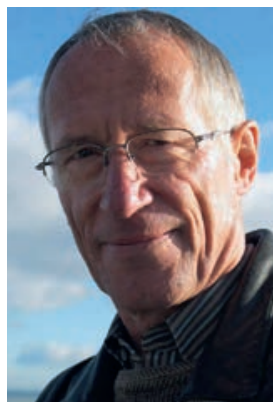

Menschen, tot oder lebendig, als Ersatzteillager und Apotheke haben eine lange Tradition. Wer in Frieden ruht, lässt eine irdische Hülle zurück, die mannigfaltig verwertet wird. Schon der ehrwürdige Paracelsus empfahl die Mumia Vera Aegyptica als Allerheilmittel. Das Geschäft mit den Einbalsamierten blühte bis in die 1920er Jahre. Pulver zum Gurgeln oder als Nahrungsmittelzusatz, ein Exportschlager mit hohen Gewinnmargen. Die Journalistin und Historikerin Janine Kopp promovierte 2012 in Luzern mit der Dissertation zum Thema "Hingerichtet und als Medikament verkauft». Die unterschiedlichsten Körperteile fanden im 16. und 17. Jahrhundert Verwendung. Ein Geschäft, das legal nur den Apothekern erlaubt war, etwa die Herstellung von Salben aus dem Fett oder Pülverchen aus den Hirnschalen der Gehenkten. Gemäss anderen Quellen sollen in Italien Apotheker getrocknetes und abgehängtes Muskelfleisch im Kamin geräuchert haben.

Heute geschieht das alles hochsteril und gesetzlich geregelt, über Firmen wie Tutogen Medical $\mathrm{GmbH}$ in Deutschland, das Unternehmen mit dem breiten Portfolio für biologische Lösungen. Tiefgekühlt kommt die Ware aus der Klinik an die Werkbank im Isoliertrakt. Aus Menschenknochen entstehen Spongiosachips und Dübel oder aus der Haut von Oberschenkeln Netze für Bauchwandeingriffe. Mit Kühlboxen voller Leichenteile aus der Ukraine ist es vorbei, seit ein Leichenhändler in den USA im grossen Stil krebsbefallene und HIV-infizierte Knochen mit gefälschten Papieren unter anderen auch an die amerikanische Mutterfirma von Tutogen lieferte. Der Gewebehandel mit Sehnen, Haut, Knorpel, Knochen oder einem Stück Aorta als Herzklappenersatz ist trotzdem eine Wachstumsbranche. Mit Leichenteilen eines einzigen Menschen lassen sich angeblich bis zu 250000 Dollar verdienen.
Die Tageszeitung Blick weiss es wieder einmal schneller als alle anderen. Die Asche Kremierter ist eine neue Bonanza. Solothurn und Zürich schürfen darin nach Gold, Platin und anderen Edelmetallen. Der Erlös geht an die Staatskasse. Auf eBay gibt es lange Listen gebrauchter Implantate. Nur Herzschrittmacher müssen schon vor der Einäscherung im Aufbahrungsraum entfernt werden. Die explodierende Lithiumbatterie kann die Ofenwand beschädigen. Die eingesammelte Elektronik geht an den Hersteller zurück. Gesucht sind Titan aus den Zahnimplantaten, Zirkonoxid, Stahl aus Marknägeln, Schrauben und Platten, Chrom, Molybdän, Cobalt, Palladium. Nach dem 900-1300-GradFeuer im Elektroofen beginnt das Filtern und die magnetische Sortierung. Zahn- und Schmuckgold, Silber, Palladium und Platin für Knopfprothesen, Zahnspangen oder Brücken. Was beim Gehen half, dient jetzt dem Kauen und den Gebisskorrekturen. Funktionale Unsterblichkeit, wenn ein Metall von einer Generation zur nächsten wandert. Recyclingfirmen gibt es mehrere. Die Rechtslage ist unklar, für Solothurn zum Beispiel sei die Asche ein herrenloses Gut, worauf kein Erbanspruch bestehe. Wie üblich pflegt da jeder Kanton sein eigenes Gärtchen. Fehlt nur noch, dass man mit der Asche die städtischen Rabatten düngt oder auf dem Friedhof vereiste Fusswege bestreut.

Kannibalen geniessen mehr Sympathie als Leichenfledderer. Wenn der tote Mensch im Wiederverwertungszyklus ausgebeutet zur Ware wird, hat das tiefgreifende Folgen für die noch Lebenden. Zwar macht in diesem Kreislauf jeder seinen Profit, doch etwas Wichtiges geht dabei mit Hilfe der modernen Medizin verloren.

\footnotetext{
Literatur

- Janine Kopp, Menschenfett - Der medizinische Körper als Arz neimittel, 2014, im Eigenverlag.
} 